\title{
Multilingual elite-interviews and software-based analysis
}

\section{Problems and solutions based on CAQDAS}

\author{
Rudolf R. Sinkovics \\ Manchester Business School \\ Elfriede Penz \\ Vienna University of Economics and Business
}

Qualitative international research is increasingly popular in marketing, management and business practice. Cultural dimensions, most importantly language, play a central role in this research context. The importance of language in the context of questionnaire design and international data gathering has long been stressed in various sources (Pike 1966; Brislin 1970; Piekkari \& Welch 2004). However, the practice of qualitative data collection and analysis has not been addressed sufficiently, although new and innovative software-based tools are available to help these efforts. This paper deals with methodological and practical issues in analysing qualitative interviews with corporate elites. We illustrate conceptual challenges in setting up qualitative projects that build on interviewing corporate elites and address practical implementation issues in terms of multilingual coding, node creation and theory building by means of computerassisted qualitative data analysis software (CAQDAS). To this end a specific empirical example will be used.

\section{Introduction and research problem}

Qualitative research in marketing and management is growing in importance, specifically in relation to work that transcends geographical and cultural borders. The implications of this trend are conceptual and practical challenges for marketing researchers and practitioners (see e.g. Sinkovics et al. 2005), whether the unit of analysis is consumers, markets or the firm. Miles (1979) points out that qualitative data are an 'attractive nuisance' since they offer real and full insights into phenomena

Received (in revised form): 09 October 2010 
- however, they require painstaking efforts to collect, collate and analyse. In qualitative international marketing and management research, complexities are significantly amplified due to multiple participants in the research team or network (Wilsdon 1996), the multilingual situations of data collection and analysis (Robinson 1984; Marschan et al. 1997; Luo \& Shenkar 2006), challenges in acquiring reliable interviewees from multiple countries (Piekkari \& Welch 2006), and quality criteria such as construct bias, measurement bias and lack of data equivalence (LeCompte \& Goetz 1982; Lincoln \& Guba 1984; Sinkovics et al. 2008).

Despite these specific issues, the international research methodology literature largely rests on a conceptual level (see Denzin \& Lincoln 1994; Bickman \& Rog 1997) and mostly refrains from discussions about practical and operational issues in dealing with these challenges. There are contributions that approach qualitative business research via computerassisted qualitative data analysis software ${ }^{1}$ (CAQDAS) as a means to structure and analyse qualitative interview data (see e.g. Coffey et al. 1996; Hesse-Biber 1996; Kelle 1997; Crawford et al. 2000), yet the specifics of qualitative international marketing and management research, the unique challenges in tapping into multilingual interview data from corporate elites, and how to deal with these in terms of multilingual scenarios, are hardly discussed.

In this paper we argue that CAQDAS can help in terms of facilitating analysis and interpretation of qualitative interview data obtained from corporate elites. We further posit that this can lead to improving the trustworthiness of qualitative data analysis and reporting (Sinkovics et al. 2008). The aim of this paper is therefore (1) to showcase how the formalisation and organisation of qualitative, multilingual projects can help to overcome the problems typically encountered in international market research projects, (2) how this formalisation contributes to enhancing trustworthiness in international research, and (3) how this helps in alleviating one specific challenge in the orchestration of this type of research, the challenge of multilingualism.

\footnotetext{
${ }^{1}$ Many CAQDAS tools are available for qualitative researchers. These range from simple free-form text-storage and retrieval products, such as askSAM and FileMaker Pro, or text-counting and sorting packages, such as TextPack PC, to advanced and state-of-the-art systems, such as Atlas.ti, Decision Explorer, Ethnograph, NVivo and MaxQDA. The latter products allow concept grouping and linking, and draw on features such as code banks, master lists and family trees. While software tools don't offer miraculous solutions or ready-made results without user input, these provide coding support and efficiency gains in terms of analysis and interpretation of large amounts of interview data. We use NVivo (Richards 2005) for pragmatic reasons as this specific package offers collaborative and merge features that are particularly helpful in the coordination of international fieldwork. However, the paper is not set up to advocate this or any other particular package.
} 


\section{Conceptual background}

\section{Language, management and international research issues}

Language is a very important ingredient to successful international business transactions, negotiations and management within and beyond multinational corporations. While the international marketing and consumer research literature has long recognised the importance of language in consumers' communication, persuasion and consumer decision making (McGuire 2000; Mick 1986), and some of this work has also drawn on CAQDAS (e.g. Belk 1992), the relevance of language within and between international firms has not received the same amount of attention. Marschan et al. (1997) argue that, despite its importance in the organisation and control of multinational corporations (MNCs), language is hardly explored empirically. Methodological considerations of how to deal with multilingualism in marketing and management research, especially how to properly exploit qualitative research designs and analyses in multilingual contexts, are difficult to come by. Feely and Harzing (2003) argue that the focus on English as 'lingua franca' in the management of multinational organisations brings the danger of ignorance of language and cultural diversity, which may contribute to 'linguistic nationalism' and pre-empt successful negotiation outcomes when dealing with Asians, South Americans and partners in the Middle East (Feely \& Harzing 2003, p. 43).

Language barriers between headquarters and their foreign subsidiaries are suggested to amplify cultural and social distance between various organisational units ('liability of foreignness') (Harzing et al. 2010), and limit effective negotiation outcomes and cooperative intra-firm relationships (Luo \& Shenkar 2006). The literature on strategic management and on communication has gravitated towards an appreciation of the importance of language for business and management (Dhir \& Goke-Pariola 2002; Luo $\&$ Shenkar 2006), thus within multinational companies we increasingly witness movements towards reference or corporate languages (Luo \& Shenkar 2006).

A large proportion of qualitative international marketing and management research builds on the premises of interviews with corporate managers, hence textual transcripts of interviews with corporate elites (Welch et al. 2002; Sinkovics et al. 2005). This stems from the fact that international research is often geared towards strategic issues, which are best attended to by top management and elite interviewees at the top of organisational hierarchies (Spencer 1973; Yeung 1995). At the same time it is found 
that corporate elites are happier allocating time to open interviews rather than providing responses to overly structured, quantitative questionnaires (Yeung 1995; Peterson 2004).

However, conceptually, multilingualism in qualitative international research poses a number of challenges. These are a function of the interaction of (1) multiple research teams, (2) cultural contexts within which the research takes place and (3) multiple reference/corporate languages that are used in the organisation under scrutiny.

\section{Multiple culture-contexts}

The design of international marketing research that transcends one single national culture context is invariably more complex. Craig and Douglas (2005) point to the importance of defining appropriate units of analysis and/or market segments that are comparable. This issue, termed 'equivalence', is widely discussed in the international marketing research literature (Holzmüller 1995; Salzberger \& Sinkovics 2006) and is reconsidered here in the context of qualitative research.

\section{Multiple research teams}

International research projects that are planned, administered and coordinated by only one researcher or research team, are less challenging than those where multiple - multilingual - research teams are involved. There is enormous pressure to synchronise, and multilingualism in research teams amplifies the challenges.

\section{Multiple reference and corporate languages}

MNCs operate across multiple markets, and therefore multiple agents, managers and partners from diverse cultural traditions, whose socialisation is rooted in country-specific experiences interact with one another (Dhir \& Goke-Pariola 2002). Given that language determines managers' capability to interact and coordinate within the multinational company context, many MNCs have developed corporate language standards. These standards and policies are advantageous from the perspective of international researchers, since they allow undertaking research in only one corporate language. However, this is only a theoretical advantage, which does not always play out in the empirical research practice. Managers often feel more comfortable responding to interviews in their mother tongue. Also, it might be more beneficial in terms of value of information to conduct elite interviews in a context where interviewer and manager both feel comfortable. 
Taken together, these issues are of prime importance for the quality of qualitative data collection, resulting textual material and subsequent use and analysis. When applying textual data to CAQDAS such as NVivo, coding of multilingual text data using equivalent language terms and developing a synchronised set of categorisations (nodes) ${ }^{2}$ is also important.

\section{Equivalence issues in qualitative analysis}

In quantitative work, a great deal of emphasis is placed on the 'operationalisation of concepts'. This is the process of defining a fuzzy concept so as to make the concept measurable and to understand it in terms of its empirical observations. In qualitative international work these operationalisations may not be as explicit, as interview guidelines and detail responses are usually not reported, and thus can easily be overlooked. Normally, qualitative interviews of corporate elites are organised such that open-ended questions are asked. These are deemed to elicit responses in connection with unclear, not properly defined phenomena. The response is expected to triangulate and contextualise phenomena that might subsequently be subjected to more rigorous analysis. Problems of construct bias, method bias and equivalence are thus equally important for qualitative research, although somewhat hidden in the background. The concepts are strongly interrelated (Poortinga 1989). If construct or method biases are present, this implies that certain factors obstructed equivalent measurement. Construct bias can occur when there is an incomplete overlap of definitions of the construct across cultures and response to open-ended questions does not lead to equivalent responses. Method bias may develop out of different social desirability levels or differential response styles such as extremity scoring and acquiescence (Hui \& Triandis 1989). Piekkari and Welch (2004) are particularly concerned with language proficiency and the language dynamics of crosscultural researchers in interview situations, which in a quantitative context corresponds to 'stimulus' bias.

Equivalence and equivalence issues are widely discussed in quantitative and questionnaire-based research (Salzberger \& Sinkovics 2006). This area of concern is similarly important when analysing textual data from interviews with corporate elites. For international business researchers, who build on interviews from across multiple countries, this implies that

\footnotetext{
${ }^{2}$ Nodes are codes that are introduced by the researcher as a result of the coding process. These provide storage areas in NVivo for references to coded text (Bazeley 2007), often referred to as 'containers of thought'.
} 
their interview data have to be obtained in equivalent ways. Furthermore it is imperative to integrate interview transcripts in comparable systems of codes. NVivo is well suited to this because it supports work in multiple groups, includes a 'merge' function for data and node systems, and thus stands out for qualitative international research. The overall goal is to compare country results with one another. Equivalence of qualitative interview data is a necessary condition for this.

\section{An example of software-based analysis}

In the following, the concepts of data equivalence within the context of qualitative expert interviews will be illustrated. The example refers to negotiation strategies in mergers and acquisitions (M\&As) in multinational companies from the perspective of involved managers. In particular, issues such as cultural and language diversity and respective barriers will be used to showcase the use of CAQDAS.

The typology, which was described in the conceptual background, shows the complexity of international market research projects, which determines qualitative, international and, most often, multilingual interviews. CAQDAS helps to structure and integrate the three outlined areas (research team, cultural context, company language). In the following, the software package NVivo (Richards 2005) will be employed to assist in a qualitative analysis (i.e. multilingual codification, building up a node system and consequently building theory). Figure 1 positions NVivo in relation to the content of research and its language-specific particularities.

NVivo

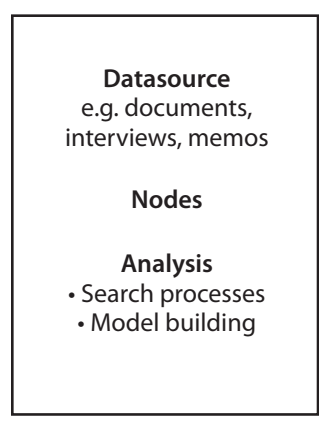

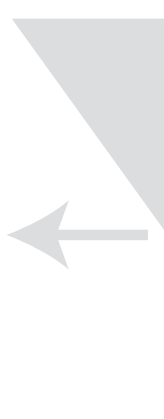

Research content

1. Categorisation

- a priori/a posterior

2. Build-up of node system

3. Integration of node system
Language-specific issues

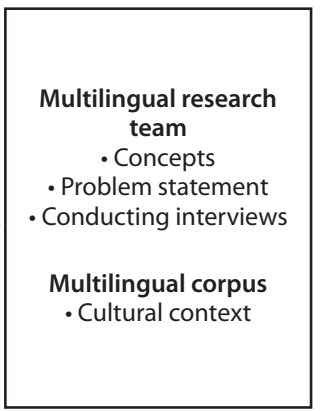

Figure 1 Sequence and integration of steps in analyses using NVivo 


\section{Research design}

Corbin and Strauss's 'grounded theory' (Corbin \& Strauss 1990; Strauss \& Corbin 1994, 1998) provides a practical methodological foundation for the present study. In the design of the study we focus on the interpretive process by analysing 'the actual production of meanings and concepts used by social actors in real settings' (Gephart 2004). NVivo facilitates the exchange of the involved research teams and their various cultural backgrounds. A team of researchers may create individual projects, for example in different languages or stages, and can merge them in NVivo without losing any data. The structure and the content of the project can be linked in a single project, and any repetitive or redundant element of the project can be deleted at a later stage. This enables the researchers to manage sub-projects in a flexible way. Reasons for creating individual projects first off and then consequently merging them in single projects derive basically from the various ways of collecting data (i.e. the corpus construction) and analysing them accordingly.

\section{Sampling and procedure}

The sample consisted of four multinational companies in which M\&A activities had recently taken place. The company selection was based on company size, geographical location and its core business. The rationale for selecting companies from Austria, the UK and Italy was to learn about management, negotiation and communication idiosyncrasies in geographically close yet psychographically heterogeneous environments (Hallén \& Wiedersheim-Paul 1979), which may potentially lead to paradoxical results regarding the performance outcomes (O'Grady \& Lane 1996).

Within the companies, those managers that were actively involved in the M\&A negotiations were contacted and asked to serve as informants. In one company three managers from different subsidiaries in the UK and Italy were willing to collaborate. In the other companies one responsible manager was found (in the UK and in Austria). The managers were contacted, either by telephone or personally, and asked to participate in the study. In total, seven interviews in companies from three countries were conducted. Three Austrian, one Italian and two British managers were interviewed. The complexities of the languages involved are illustrated in Table 1.

The interviewees were managers at the top and middle management level, and responsible (either directly or as part of a team) for the 
Table 1 Information on interviews

\begin{tabular}{|c|c|c|c|c|c|c|}
\hline Company & Interview in & $\begin{array}{l}\text { Corporate } \\
\text { languages }\end{array}$ & $\begin{array}{l}\text { Interview } \\
\text { language }\end{array}$ & $\begin{array}{l}\text { Mother } \\
\text { tongue } \\
\text { interviewee }\end{array}$ & $\begin{array}{l}\text { Management } \\
\text { level }\end{array}$ & $\begin{array}{l}\text { Mother } \\
\text { tongue } \\
\text { interviewer }\end{array}$ \\
\hline AustriaCo1 & $\mathrm{HQ}$ (Austria) & $\begin{array}{l}\text { German } \\
\text { English }\end{array}$ & German & German & CEO & German \\
\hline AustriaCo2 & $\mathrm{HQ}$ (Austria) & $\begin{array}{l}\text { German } \\
\text { Italian }\end{array}$ & German & German & $\begin{array}{l}\text { Middle } \\
\text { manager }\end{array}$ & German \\
\hline UKCo1 & $\begin{array}{l}\text { Subsidiary } \\
\text { (Austria) }\end{array}$ & English & English & English & $\begin{array}{l}\text { Regional } \\
\text { manager }\end{array}$ & English \\
\hline \multirow[t]{3}{*}{ UKCo2 } & HQ (UK) & English & English & English & CEO & English \\
\hline & HQ (UK) & English & English & German & $\begin{array}{l}\text { Business } \\
\text { developer }\end{array}$ & Italian \\
\hline & $\begin{array}{l}\text { Subsidiary } \\
\text { (Italy) }\end{array}$ & $\begin{array}{l}\text { English } \\
\text { Italian }\end{array}$ & Italian & Italian & $\begin{array}{l}\text { Country } \\
\text { manager }\end{array}$ & Italian \\
\hline
\end{tabular}

company's M\&A activities. We followed the principles of 'theoretical sampling' (Glaser \& Strauss 1967), which implied that we included additional samples sequentially, in order to confirm or disconfirm aspects of our emerging framework (Creswell 1997). By contrasting manager responses from different company sectors, external validity was assessed. Therefore, after an initial interview with a manager from the pharmaceutical sector, subsequent interviews were conducted with managers in similar companies (pharmaceuticals) and with firms that exhibited complementary backgrounds (e.g. industrial goods). Our search for additional informants, i.e. managers who were indirectly involved in M\&As, reflects an iterative process that adds additional material to the text corpus in the form of 'strata of people' or new texts (Bauer \& Aarts 2000, p. 19).

At the start of the study the meaning and the importance of M\&As was discussed with the managers responsible and, additionally, companyspecific information from websites, including international subsidiary information or media reports, was analysed with respect to conceptual and functional equivalence. Based on the information collected, we found that, between and within the selected companies, the concept was understood and defined very similarly; slight differences were due to the responsibilities of the respective managers and the overall area of business.

The interviews were held in the offices of the interviewees in either English, German or Italian. With respect to the physical context, this was standardised to the managers' offices, and the interviews lasted between one and two hours each. In order to guarantee replicability, data 
were digitised, tape recorded and transcribed in their original language. Additionally, each interviewer provided a short summary of the interview in English as separate document.

\section{Data collection: corpus construction}

With respect to data collection we standardised the process in such a way that equivalence of research methods, units and administration was ensured. Cross-cultural issues were discussed in two extensive training meetings and outcomes incorporated as annotations ('memos') in the NVivo project. This ensured that the information was accessible at any time. A laddering-type interview process (Grunert \& Grunert 1995) was encouraged in order to facilitate the clarification of issues, verification of interpretation of answers during the interview, and persistence in following up on emerging topics and themes arising during the interview (Rubin 1995; Kvale 1996; Strauss \& Corbin 1998; Arksey \& Knight 1999; Lee 1999). Interviews were conducted and transcripts prepared in the original languages (English, German or Italian).

To establish construct validity (Lee 1999), three steps were applied: first, providing multiple sources of evidence; second, establishing a chain of evidence; and, third, providing feedback to key informants (Yin 2003).

First, interviewees' comments, observations of the interview setting and contextual factors (physical factors such as building, entrance, etc.) were noted in English and added to the NVivo project as memos. The infrastructure of the office was observed, taking note of the behaviour or the language of employees. Using these multiple sources of evidence increased construct validity. From a technical point of view this proved useful because the observations could be accessed at any time and shared among the research team, who later included such information in the analysis. In addition, researchers used NVivo memos to document the relevance of the collected information to the overall research question. Each researcher was instructed to rate the sources according to the concept being studied. Then the comments were discussed and a common rating in English of the operational measures used was established.

Second, a 'chain of evidence' was applied to establish construct validity, i.e. assuring a logical, sequential process that can be reconstructed and anticipated by an external audit (Lee 1999; Yin 2003), including for example field notes about the contact situation (how many times had he/ she to call to talk to the manager), and observations regarding atmosphere and the first impression, and scheduling the interview. These observations 
were an important part of the project, since they helped in developing an idea about the relationship between managers and employees even before the interviewees' answers were analysed. Hence, multiple elements of information converged and indicated high construct validity.

Third, key informants reviewed the preliminary reports and observations of the researchers, which, somewhat surprisingly, allowed them to obtain useful and interesting information about the M\&A negotiations. The information proved helpful in reflections about the topics and no objections were raised regarding the content. All participants agreed to continue participation in follow-up research.

To increase the reliability of the study, researchers followed a protocol (Yin 2003) that facilitated the repeatability and replicability of procedures. An important issue in the documentation of the project was the company language. The interviewed manager in the Italian subsidiary, for example, preferred to talk in Italian, although the company language was English. This was possible since the informants were free to choose the interview language. Additional data (company data, reports, etc.), however, was available in English resulting in a multilingual text corpus.

\section{Analysis}

The data analysis involved the formalised steps organising, coding, searching and modelling. To begin with, organising steps helped to set up a project in NVivo, including textual material from the in-depth interviews in the original language, written observations as recorded by the interviewers and company information. Three researchers formed the core team of analysts, each one a native speaker in one of the languages used (English, German or Italian). However, all of them were also knowledgeable about the other two languages, which was important in developing a common coding scheme.

Within NVivo the section 'attributes' (classifications) was used in addition to the qualitative text material to organise company characteristics. Hence, quantitative information, which provided overall insights into company background and organisational structure, was included. Such data included age and size (number of employees, sales turnover) of the company, industry sector, main products (obtained via company brochures, etc.), market position (market leader, leading player of many, niche player, etc.) as well as the number of international markets the company is in and its approximate length of time in international markets. 
The data collected were subsequently coded, which was the most crucial step in the analytical process. The coding process is an ongoing interpretation and examination of textual data from different perspectives. It is dependent on the number of researchers involved. Two coding strategies were used, namely a priori and a posteriori categorisation of data. We started out with a priori categorisation, which concerned the development of English categories prior to actual data collection, based on theory, literature and exploratory interviews with experts in the field. With multiple language contexts employed, research languages had to be synchronised and managed appropriately at various stages of our research, i.e. in the problem formulation, the research design development, and in the planning and administration of data collection (Iacobucci \& Churchill 2010). A posteriori categorisation was then involved subsequent to the data collection in Austria, the UK and Italy. Empirical indicators were developed based on the multilingual data and uses in subsequent analysis stages.

The research project was overseen by one university partner located in the UK. Crucial questions, such as design and implementation of empirical work, were orchestrated from the UK, which helped to reduce potential coordination problems with partner institutes. However, implementation decisions that were outside the formal agreement and difficult to control centrally (e.g. the adaptation and translation of the interview guideline to the Italian context or the recruiting of interview partners) were taken locally. The project team analysed the corpus employing different research perspectives. One researcher, for example, analysed the text from a linguistic point of view; others performed content analyses or applied coding strategies following a 'grounded theory' perspective. In the following, examples of the coding process are illustrated to provide some guidance.

Interview languages were retained, as well as initial codes. However, the codes were also transformed and merged into English, the common language of analysis. Idiosyncratic aspects of codes were retained throughout the coding process (e.g. terms such as 'Wellenlänge' in German, see Figure 2). This aided understanding of the multiple-culture context. It also facilitated further analysis and comparability checks, as well as allowing us to retain language- and culture-specific aspects. Also, this augmented reliability because categorisation decisions were discussed in English, a language that fits all researchers and participants in the project. The derived categorisation scheme was continually discussed, monitored and updated with the co-analysts. This procedure safeguarded against the danger of a purely uniform coding scheme as in the 'etic' school of 
thought, ${ }^{3}$ which would not have allowed for the identification of country specificities and equivalence of data.

Decisions about the size of the node system required us to find a balance between breadth and depth. The node system is a function of the stage of the research process and evolves over time (Marshall 2002). Hence, each text section was analysed with more scrutiny, following open, axial and selective coding processes, as suggested in the literature. Open coding is usually used for the discovery of categories and the identification of new concepts. In this stage of the categorisation process, each researcher freely added categories, which were discussed in a meeting afterwards. Axial coding applies categories and concepts to empirical data. Here, categories are related to their subcategories, and intersections of related categories are identified. The objective of axial coding is to add depth to categories.

Finally, selective coding - the process where categories are integrated and refined in order to build a theory - was applied. Therein concepts were established and statements used to explain the phenomenon of interest. The textual data were reduced and a desirable level of abstraction was reached for our research (Strauss \& Corbin 1998; Lee 1999).

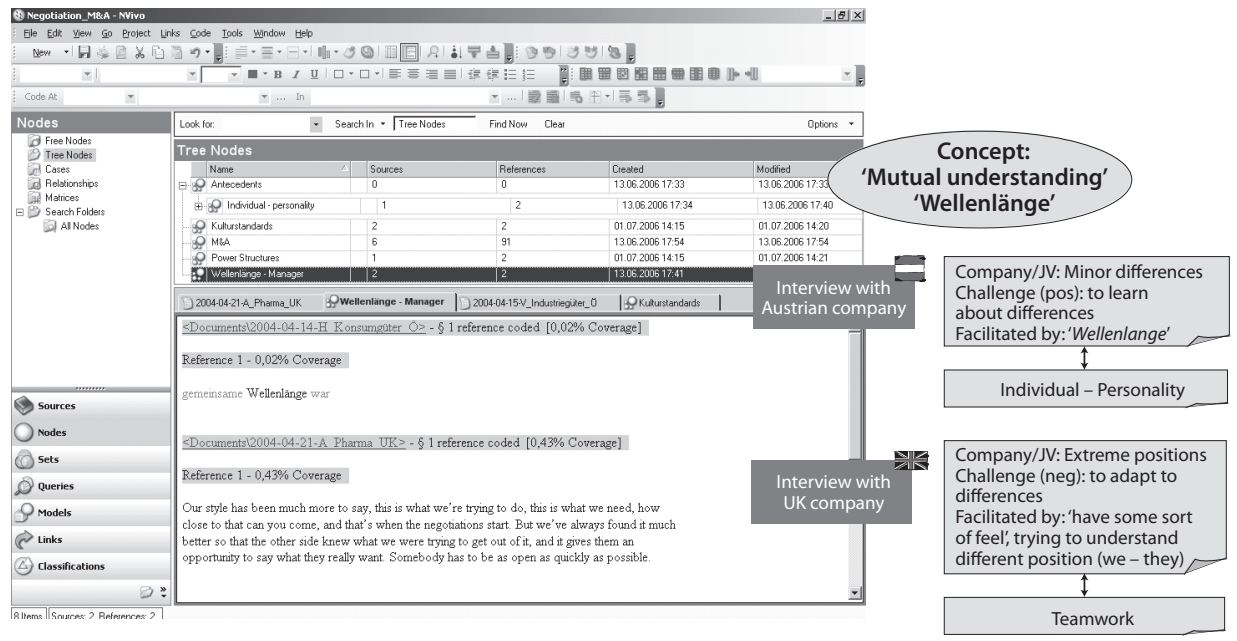

Figure 2 Illustration of conceptual differences due to language

\footnotetext{
${ }^{3}$ With respect to the term 'etic', this refers to the 'emic' and 'etic' schools of thought, which have been introduced in the literature to cope with the challenges of comparisons. Etic and emic represent two extremes on the continuum of international research methodology. 'Etic' research is primarily concerned with the identification and assessment of universal concepts and the development of 'culture-free' measures. The main purpose of 'etic' approaches lies in comparisons, thus loss of cultural specificity ('emic') is accepted in this type of research (Denzin \& Lincoln 1994; Sinkovics \& Holzmüller 2001).
} 
Extensive codification and node building is an important foundation for checks of equivalent conceptualisations, as the understanding of concepts may vary within the multilingual research team, the cultural context and the company language (see Figure 2). The codes 'mutual understanding' and 'Wellenlänge', for instance, exemplify that, with respect to negotiation styles in M\&As, managers agree on this important contextual M\&A negotiation element. However, when inspecting the content and the context in which the respective statements were given, it becomes clear that the English code (mutual understanding) refers to collaboration, whereas the German code (Wellenlänge) expresses an individual's view. This difference emerges because original terms were used, but could not become clear if only one language were used for coding. Figure 2 shows the different concepts and provides a screenshot from the software for illustrative purposes.

The next step was to theorise about the content by searching the NVivo project. Searching a project refers to the process of conducting queries within the text data. For example, a simple text search within NVivo for, e.g., 'collaboration' retrieves all the sections in the interview data where the term is found, including text passages prior to and after the search term. To this end the search results can serve as a node/container for further codification. This process is valuable in terms of building an informed understanding of interview responses within one interview, but also between interviews. The search and retrieval process thus supports theorising, because it helps the researcher to engage in a 'dialogue with the computer' that facilitates an understanding of the interview data that is arguably more easily obtained than with a standard pencil-andpaper method. Due to the multilingual requirements (research team, text corpus), the software needs to conform to multilingual expressions, which implies that researchers have to take care about interpreting and coding text with equivalence of meaning in mind. Furthermore, the key terms of negotiation strategies, communication and management styles in M\&As, which were obtained in the node building process, constituted the background for the analytical search processes, such as 'negotiation skills' or 'Machiavellianism'.

Search outputs can be used to conduct further, more quantitatively inspired analysis (using, e.g., SPSS). This practice is not suggested to quantify qualitative data, as this would not serve qualitative studies well (Pratt 2009), but it may help in enriching existing qualitative findings with additional descriptive insights. In our case, search processes were further used for country-comparative and language-specific analyses. 
The ensuing example demonstrates the issue of construct bias: power emerges as focal construct, as far as problems and solutions in the negotiation phase are concerned. For a UK firm involved in M\&A negotiation with a Swedish partner, less hierarchical and more democratic power exertion becomes visible. The UK manager talks about being 'the boss' and realises cultural differences as he relates to 'the others, the Swedes' who are used to democratic leadership:

Interviewer: Do you think that you had different power of what you can actually bargain about compared to the [other company's] people?

Manager: Well, in a merger implementation, it's different, because it was a straightforward management hierarchy so I was the boss, so in the end I could decide. And one of my favourite phrases was to say 'we have a discussion, but this is not a democracy'. However, the Swedes were slightly more used to a democracy. So the struggle was one of cultural change. On my management team it wasn't only Swedes of course, there were British people, one Frenchman, one Belgian. I've forgotten already because it was so long ago, but it was actually quite a disparate cultural mix which helped.

He introduced 'meetings' instead of individually managing, and thus introduced teamwork:

The other example was when I went there, there weren't any management meetings of that team, or any getting-together - it was all sort of individually done. So I introduced, once a week, those who were present would get together in my office just to talk over what was going on.

In contrast, an Austrian manager from the fast-moving consumer goods (fmcg) industry leads the M\&A negotiation and uses his hierarchical power as a negotiation strategy:

The whole negotiation process often starts with hierarchical 'Weichenstellung', ${ }^{4}$ a strategic setting of the configuration and tone and following course of action. This is where a key person from the upper echelon is required. If this individual enters the stage and makes very distinctive, uncompromising comments at the end of a negotiation process, everybody involved knows that the negotiation goals have finally been met and there is nothing more to debate. This is a function of drawing on organisational hierarchy. We use it, selectively, but with power and effectiveness.

\footnotetext{
${ }^{4}$ This relates to the German interview responses: 'Weichenstellung', literally translated means the setting of switches for trains. Thus it refers to a strategic change in the course of action.
} 
Thus, based on different languages and meanings of texts, as well as idiosyncratic codes, multilingual researchers discussed the emerging constructs by suggesting codes and appropriate descriptions. Emerging codes were structured to reflect conceptually relevant meanings in such a way that both generalisability as well as idiosyncrasy of the M\&A negotiation issue were retained. The main features in the NVivo CAQDAS system were the node system, sources and attributes; applied processes referred to inspecting and discussing the node systems, as well as running queries.

The final step in the analysis helped in the development of graphical models using documents, nodes, attributes and memos. This process is called 'model building' in NVivo and is facilitated by the software. The model-building feature draws on the existing nodes that are developed during the coding process and manages the visual representation of nodes in a two-dimensional graphical space. Modelling was also instrumental for the conceptualisation of ideas that arose during the ongoing coding and search process. Modelling assisted to design the project and helped in graphical exploration of the research process. Finally, visual representation helped to overcome codification or language problems within the team of researchers. Models in NVivo were evolving, continually changing, refined by the researcher and updated according to the research progress.

\section{Discussion}

This paper deals with multilingual interviews and software-based analysis, drawing on the CAQDAS tool NVivo. Multilingual interviews with elite respondents become increasingly important as a function of the interdependence of international markets and business. Some industry case studies suggest that innovative and CAQDAS-based approaches can help to deal with multiple sets of interview data from geographically dispersed customers. Progressive Sports Technologies, a sports innovation consultancy that specialises in the research and design of cutting-edge fitness equipment for major global sports brands like Nike, Reebok and Speedo, for instance, reports that the use of NVivo helped to identify innovative new designs (QSR International 2010b). Banarra, a sustainability assurance consultancy, is contracted by big business to rigorously audit its stakeholder and sustainability reports and systems to ensure that they are focusing on and responding to the right issues. The utilisation of CAQDAS approaches has helped Banarra to improve its proprietary assurance methodology and excel beyond competitors (QSR International 2010a). Despite the existence 
of few case studies such as these, the literature suggests that more help in dealing with the practical issues of this type of research is needed (Bruno 2008; Lewins \& Silver 2007).

In order to showcase how the formalisation and organisation of qualitative, multilingual projects can help to overcome the problems typically encountered in international market research projects, we illustrated a qualitative project, based on elite interviews with managers who participated in M\&A negotiations in multinational companies. We argue that this formalisation of qualitative research projects can help to enhance trustworthiness in international research, and discuss specific issues of data equivalence and practical issues of implementing multilingual interviewing, coding and node creation as well as theory building.

A CAQDAS-based approach is considered appropriate in alleviating the challenge of orchestration of this multilingual research, because it supports structuring and systematising of the research process (Sinkovics et al. 2008). We argue that a CAQDAS-based approach helps to deal with the multidimensionality of research team(s)/cultural context(s), and reference or corporate language. NVivo encourages the taking of very concrete decisions in the process of coding multilingual text data, which leads to synchronised nodes and attributes between multiple research teams, within the text data and improvements in terms equivalence of interview data overall.

A further argument for following a CAQDAS-based approach is that it is very well suited to longitudinal studies as well as follow-up research. Data that are collected at different points in time can be easily integrated in the research project - e.g. if the principle of 'theoretical sampling' is followed - and explored using existing search-terms, nodes and attributes. Existing projects can also serve as a solid basis on which to build future research projects and inquiries. While the focus of this project was negotiation strategies in the context of M\&As, future studies could benefit by extending findings to other contexts. Practically existing project structures in NVivo (e.g. node structure, attributes and sets) can be used to build and extend research questions to other topics of interest.

In the course of sampling, data collection and all three analytical steps (categorisation, building up a node system, and integration of the node system), multilingualism proved quite challenging. However, it enriched our understanding of M\&A negotiation strategies, which would not have been possible had we relied solely on monolingual insights (through translation). In this paper we argue that language and culture specificity are 
important dimensions to be taken care of in multilingual elite interviews and their analysis.

As suggested with reference to companies that are already utilising CAQDAS in their organisations, there are specific advantages for business in deploying the opportunities of software-based approaches to qualitative research. Many companies outsource market and business research to external professionals. CAQDAS such as NVivo allows primary data to be combined with internal data. Qualitative NVivo projects support the integration and tracking of sources, and allow a more holistic understanding of research issues from a multi-stakeholder perspective. In view of the unprecedented multilingual research landscape, CAQDAS such as NVivo offer an excellent toolbox for the administration and analysis of various types of qualitative information sources, e.g. text data, websites, images and videos.

\section{References}

Arksey, H. \& Knight, P.T. (1999) Interviewing for Social Scientists. Thousand Oaks, CA: Sage Publications.

Bauer, M.W. \& Aarts, B. (2000) Corpus construction: a principle for qualitative data collection. In: M.W. Bauer \& G. Gaskell (eds) Qualitative Researching with Text, Image and Sound. London: Sage, pp. 19-37.

Bazeley, P. (2007) Qualitative Data Analysis with NVivo. London: Sage Publications.

Belk, R.W. (1992) Moving possessions: an analysis based on personal documents from the 1847-1869 Mormon migration. Journal of Consumer Research, 19, 3, pp. 339-361.

Bickman, L. \& Rog, D.J. (1997) Handbook of Applied Social Research Methods. London: Sage Publications.

Brislin, R.W. (1970) Back translation for cross-cultural research. Journal of Cross-Cultural Psychology, 1, 3, pp. 185-216.

Bruno, I. (2008) Review of: Lewins, A. \& Silver, C. (2007) Using Software in Qualitative Research: A Step-by-Step Guide. London: Sage Publications. Sociological Research Online, 13, 3. Online at: http://www.socresonline.org.uk/13/3/reviews/bruno.html (accessed 1 August 2011).

Coffey, A., Holbrook, B. \& Atkinson, P. (1996) Qualitative data analysis: technologies and representations. Social Research Online, 1, 1. Online at: http://www.socresonline.org. uk/1/1/4.html (accessed 1 August 2011).

Corbin, J. \& Strauss, A. (1990) Grounded theory research: procedures, canons, and evaluative criteria. Qualitative Sociology, 13, 1, pp. 3-21.

Craig, C.S. \& Douglas, S.P. (2005) International Marketing Research (3rd edn). Chichester: John Wiley \& Sons.

Crawford, H.K., Leybourne, M.L. \& Arnott, A. (2000) How we ensured rigour in a multi-site, multi-discipline, multi-researcher study. Forum: Qualitative Social Research, 1, 1. Online at: http://www.qualitative-research.net/index.php/fqs/article/view/1122 (accessed 1 August 2011).

Creswell, J.W. (1997) Qualitative Inquiry and Research Design - Choosing among Five Traditions. London: Sage Publications. 
Denzin, N.K. \& Lincoln, Y.S. (eds) (1994) Handbook of Qualitative Research. Thousand Oaks, CA: Sage Publications.

Dhir, K.S. \& Goke-Pariola, A. (2002) The case for language policies in multinational corporations. Corporate Communications, 7, 4, pp. 241-250.

Feely, A.J. \& Harzing, A.-W. (2003) Language management in multinational companies. Cross Cultural Management, 10, 2, pp. 37-52.

Gephart, R.P. (2004) Qualitative research and the Academy of Management Journal. Academy of Management Journal, 47, 4, pp. 454-462.

Glaser, B.G. \& Strauss, A. (1967) The Discovery of Grounded Theory: Strategies of Qualitative Research. London: Weidenfeld and Nicholson.

Grunert, K.G. \& Grunert, S.C. (1995) Measuring subjective meaning structures by the laddering method: theoretical considerations and methodological problems. International Journal of Research in Marketing, 12, 3, pp. 209-225.

Hallén, L. \& Wiedersheim-Paul, F. (1979) Psychic distance and buyer-seller interaction. Organisajon, Marked og Samfund, 16, 5, pp. 308-324.

Harzing, A.-W., Köster, K. \& Magner, U. (2011) Babel in Business: the language barrier and its solutions in the HQ-subsidiary relationship. Journal of World Business, 46, 3, pp. 279-287.

Hesse-Biber, S. (1996) Unleashing Frankenstein's monster? In: R. Burgess (ed.) Studies in Qualitative Methodology: Computing and Qualitative Research, Vol. 5. London: JAI Press, pp. 25-41.

Holzmüller, H.H. (1995) Konzeptionelle und Methodische Probleme in der Interkulturellen Management- und Marketingforschung. Stuttgart: Schäffer-Poeschel.

Hui, H.C. \& Triandis, H.C. (1989) Effects of culture and response format on extreme response style. Journal of Cross-Cultural Psychology, 20, 3, pp. 296-309.

Iacobucci, D. \& Churchill, G.A. (2010) Marketing Research: Methodological Foundations (10th edn). Mason, Ohio: South-Western Cengage Learning.

Kelle, U. (1997) Theory building in qualitative research and computer programs for the management of textual data. Social Research Online, 2, 2. Online at: http://www. socresonline.org.uk/2/2/1.html (accessed 1 August 2011).

Kvale, S. (1996) Interviews: An Introduction to Qualitative Research Interviewing. Thousand Oaks, CA: Sage Publications.

LeCompte, M.D. \& Goetz, J.P. (1982) Problems of reliability and validity in ethnographic research. Review of Educational Research, 52, pp. 31-60.

Lee, T.W. (1999) Using Qualitative Methods in Organizational Research (Organizational Research Methods Series). Thousand Oaks, CA: Sage Publications.

Lewins, A. \& Silver, C. (2007) Using Software in Qualitative Research: A Step-by-step Guide. London: Sage Publications.

Lincoln, Y.S. \& Guba, E.G. (1984) Naturalistic Inquiry. Beverly Hills, CA: Sage Publications.

Luo, Y. \& Shenkar, O. (2006) The multinational corporation as a multilingual community: language and organization in a global context. Journal of International Business Studies, 37, 3, pp. 321-339.

Marschan, R., Welch, D. \& Welch, L. (1997) Language: the forgotten factor in multinational management. European Management Journal, 15, 5, pp. 591-598.

Marshall, H. (2002) What do we do when we code data? Qualitative Research Journal, 2, 1, pp. 56-70.

McGuire, W.J. (2000) Standing on the shoulders of ancients: consumer research, persuasion, and figurative language. Journal of Consumer Research, 27, 1, pp. 109-114.

Mick, D.G. (1986) Consumer research and semiotics: exploring the morphology of signs, symbols, and significance. Journal of Consumer Research, 13, 2, pp. 196-213.

Miles, M.B. (1979) Qualitative data as an attractive nuisance: the problem of analysis. Administrative Science Quarterly, 24, 4, pp. 590-601. 
O'Grady, S. \& Lane, H.W. (1996) The psychic distance paradox. Journal of International Business Studies, 27, 2, pp. 309-333.

Peterson, R.B. (2004) Empirical research in international management: a critique and future agenda. In: R. Marschan-Piekkari \& C. Welch (eds) Handbook of Qualitative Research Methods for International Business. Cheltenham, UK: Edward Elgar, pp. 25-55.

Piekkari, R. \& Welch, C. (2004) Language dynamics in cross-cultural qualitative interviewing. Nordic Workshop in International Business, INSEAD, Fontainebleau, 26-28 May.

Piekkari, R. \& Welch, C. (2006) Guest Editors' Introduction to the Focused Issue: qualitative research methods in international business. Management International Review, 46, 4, pp. 391-396.

Pike, K.L. (1966) Language in Relation to a Unified Theory of the Structure of Human Behavior. The Hague, NL: Mouton.

Poortinga, Y.H. (1989) Equivalence of cross-cultural data: an overview of basic issues. International Journal of Psychology, 24, 6, pp. 737-756.

Pratt, M.G. (2009) For the lack of a boilerplate: tips on writing up (and reviewing) qualitative research. Academy of Management Journal, 52, 5, pp. 856-862.

QSR International (2010a) QSR International Case Study: How Software is Shaping Sustainability Assurance (online). Doncaster, Victoria, Australia: QSR International, 20 September.

QSR International (2010b) QSR International Case Study: Taking Sporting Equipment to a New Standard with NVivo (online). Doncaster, Victoria, Australia: QSR International, 20 September.

Richards, L. (2005) Handling Qualitative Data - a Practical Guide. London: Sage Publications.

Robinson, P. (1984) Language in data collection: difficulties with diversity. Journal of the Market Research Society, 26, 2, pp. 159-169.

Rubin, H.J. (1995) Qualitative Interviewing: The Art of Hearing Data. Thousand Oaks, CA: Sage Publications.

Salzberger, T. \& Sinkovics, R.R. (2006) Reconsidering the problem of data equivalence in international marketing research: contrasting approaches based on CFA and the Rasch model for measurement. International Marketing Review, 23, 4, pp. 390-417.

Sinkovics, R.R. \& Holzmüller, H.H. (2001) National differences in materialism - using alternative research strategies to explore the construct. Journal of International Consumer Marketing, 13, 2, pp. 103-134.

Sinkovics, R.R., Penz, E. \& Ghauri, P.N. (2005) Analysing textual data in international marketing research. Qualitative Market Research: An International Journal, 8, 1, pp. 9-38.

Sinkovics, R.R., Penz, E. \& Ghauri, P.N. (2008) Enhancing the trustworthiness of qualitative research in international business. Management International Review, 48, 6, pp. 689-714.

Spencer, G. (1973) Methodological issues in the study of bureaucratic elites: a case study of West Point. Social Problems, 21, 1, pp. 90-103.

Strauss, A. \& Corbin, J. (1994) Grounded theory methodology - an overview. In: N.K. Denzin \& Y.S. Lincoln (eds) Handbook of Qualitative Research. Thousand Oaks, CA: Sage Publications, pp. 273-285.

Strauss, A.L. \& Corbin, J.M. (1998) Basics of Qualitative Research: Grounded Theory Procedures and Techniques. Thousand Oaks, CA: Sage Publications.

Welch, C., Marschan-Piekkari, R., Penttinen, H. \& Tahvanainen, M. (2002) Corporate elites as informants in qualitative international business research. International Business Review, 11, 5, pp. 611-628.

Wilsdon, M. (1996) Getting it done properly: the role of the co-ordinator in multi-country research. Journal of the Market Research Society, 38, 1, pp. 67-71. 
Yeung, H.-W. (1995) Qualitative personal interviews in international business research: some lessons from a study of Hong Kong transnational corporations. International Business Review, 4, 3, pp. 313-339.

Yin, R.K. (2003) Case Study Research: Design and Methods (Applied Social Research Methods Series) (3rd edn). Thousand Oaks, CA: Sage Publications.

\section{About the authors}

Rudolf R. Sinkovics is Professor of International Business at Manchester Business School, UK. He has published on inter-organizational governance, the role of ICT in firm internationalization and research methods in international business. Recent work focuses on rising powers, emerging markets firms and drivers of economic change. He received his $\mathrm{PhD}$ from Vienna University of Economics and Business (WU), Austria in 1998.

Elfriede Penz is Associate Professor at the Institute for International Marketing Management, Vienna University of Economics and Business (WU). She holds a PhD in psychology (University of Vienna), the EuroPhD on Social Representations and Communications from the Universities of Rome, Lisbon and Helsinki (2001) and a Master of Advanced Studies in Cultural Studies from Vienna University of Music and Interpretative Art. Her research focus is on consumer behaviour and international marketing, in particular she is involved in international counterfeiting and piracy studies.

Address correspondence to: Rudolf R. Sinkovics, Manchester Business School, Booth Street West, Manchester M15 6PB, UK.

Email: Rudolf.Sinkovics@manchester.ac.uk

Web: http://www.personal.mbs.ac.uk/rsinkovics 
Copyright of International Journal of Market Research is the property of Warc LTD and its content may not be copied or emailed to multiple sites or posted to a listserv without the copyright holder's express written permission. However, users may print, download, or email articles for individual use. 